\title{
Measuring Student Learning Outcomes in Introductory Project Management Course in Graduate Schools
}

\author{
Ankit A. Ravankar* , Abhijeet Ravankar ${ }^{\dagger}$, Shotaro Imai *
}

\begin{abstract}
In this paper, we discuss the learning outcomes of the graduate students in an introductory project management course. Our study utilizes survey results to determine the student's learning outcomes in terms of their cognitive thinking, critical thinking, perception, and fundamental knowledge of management studies in a trans-graduate school. We also evaluated the improvement in the student's interpersonal skills and motivation after the course. We present the methods and discuss the essential need to introduce project management practices at an early stage in graduate schools and critical dimensions of student learning experiences using pre-course and post-course survey results. The survey measures the student's ability to grasp project management core concepts and practices, and attitude towards project management in general. From our studies, several key research conclusions have been drawn with respect to the pedagogical methods. The study suggests that with a cumulative and an immersive course syllabus that involves hands-on experience, and exposure to essential concepts of project management techniques, student's self-confidence and ability to reason and handle new projects significantly i mproves. The course framework is based on problem-based learning with mixed student interactions from different backgrounds and diverse nationalities that improved their problem-solving abilities and ability to work in a team environment. The study also discusses the impact of early introduction to project management techniques and student's employability.

Keywords: Graduate School Education, Learning Measurement, Problem Based Learning, Project Management.
\end{abstract}

\section{Introduction and Background}

In the past few years, the essential skill sets required for success in the workplace have significantly changed. At present, the employers insist on a better-prepared workforce that can quickly adapt to changes, are reasonable, be a team player, and adapt to the changing competitive realities of the global economy. To cater to such a highly competitive market, most industries are actively looking for and hiring fresh graduates, particularly those who

\footnotetext{
* Faculty of Engineering, Hokkaido University, Sapporo, Japan

$\dagger$ Faculty of Engineering, Kitami Institute of Technology, Kitami, Japan

\# Tokyo Institute of Technology, Tokyo, Japan
} 
possess the necessary skills to undertake challenging roles in their work environment[1]. These skills are not just limited to the "hard skills" that the student had acquired during his or her undergraduate/graduate studies, but also the "soft skills," a special set of generic skills and competencies needed to handle any given role in the workplace and many of them require their employees to excel in such skills such as teamwork and group development [2, 3]. Due to this reason, there has been a dramatic shift in education policies around the world to transform the present education system and build a curriculum that revolves around such generic skills[4]. The emphasis is on increased performance, educational effectiveness, and accountability on student learning abilities. Also, a process to measure the achievements on such softer skills is required for sustainable growth.

There is a growing demand for project management skills as a consequence of the diversification and globalization of organizations around the world. Project management is a form of general management that enables the organizations to integrate, plan, deploy, and control schedule-intensive activities in order to improve overall profitability and organizational performance[5]. To cater to this demand, many universities have started introductory and intensive courses on project management that are more practical and offer university degrees and electives in project management training for their students. Project management training and its importance in the industry have been well studied, and there are many pieces of research to prove how project management training improves employee's efficiency and work management. Such training is essential when it comes to handling different projects and scheduled-delivery in the current global competitive market $[6,7,8]$. Industries often offer higher salaries to individuals who are trained in project management and possess soft skills that can seemingly work globally, communicate effectively, and bring new ideas to improve company sales. Corporations and industries have started training their employees regularly about the skills that a project manager should possess in order to stay in the competition through seminars and corporate training.

Though within the higher education sector, project management as a discipline has just started to evolve over the last few years, and the trend is picking up. Project management learning has mainly been confined to business and management schools and limited to more mainstream subject areas such as mechanical and civil engineering schools and one that is embedded in many management school curriculum. Indeed, a significant industry has grown up around project management training and education inside and outside of the higher education sector [9]. Even then, some studies have shared concerns that many training programs are failing to adequately teach the skills needed to manage the high-level projects that organizations demand[10]. One reason for such failure is suggested as a lack of communication skills, including effective questioning, active listening, communication analysis, and assimilation [11]. The reason also protrudes the amount of time spend during training by the employee, citing reasons that such a small training session does not produce a significant impact on the learning. At university graduate recruitment sessions, companies seek candidates who can fit any domain of offered work and stress is on communication, leadership skills, and on individuals who can work and manage projects in team [4]. In most existing programs at schools and colleges, project-based management courses are offered as specialized or generic management programs and disciplines at different levels (undergraduate and graduate). Varying levels of expertise are brought to bear on what is increasingly seen as a critical management skill. Despite the efforts, it could be argued that a dearth of project management courses and university level programs still exist. With this regard, our basis for this study is that universities can provide a great platform to train graduate students at all levels to become better project managers [12]. Most skills that are incorporated in the 
project-based training as prescribed by the Project Management Institute (PMI) and their own Book of Knowledge (BoK)[13] are close to the active learning, project/problem-based learning $(\mathrm{PBL})$ techniques that the universities are aiming for $[14,15,16]$. By introducing PM knowledge into the current PBL training system, universities can enhance the student's ability to be job market-ready with all the necessary tools and knowledge. In this study, we present a framework of a new trans-graduate school program for research universities called the "Nitobe School" system, where the aim is to produce graduates that have acquired necessary generic skills required for the market. Our focus is on introductory project management courses for graduate students in the PBL scenario. We measure the student's learning experience within the context of a comprehensive project management curriculum. We collected pre- and post-course surveys on attributes such as learning abilities, project management fundamentals, team learning, problem-solving, and interpersonal skill development with an aim to create global leaders for tomorrow.

\section{Goals of this study}

The goal of this study is to understand and measure several attributes as to what constitutes a good introductory project management course from the perspective of ease of delivery and student learning. We want to determine how student's engagement in the course and their attitudes bring changes throughout the course with emphasis on key learning parameters, namely, critical thinking, problem-solving, team learning, management foundation, and interpersonal skill development. Our key targets are -

- To determine what topics are suitable to be imparted in a single semester course that can be delivered to the students effectively? How to impart such knowledge from key concepts with an assumption that the student might not take a project management course in the future.

- To determine the student's perception of project management as an asset and how their attitude changes during the course. Do students appreciate the value of gaining such training and how it can shape up their future as professionals when entering the organizations after university? Furthermore, if they will be willing to continue their education on project management practices in the future.

- Lastly, we want to determine how as a faculty, this course can bring subtle changes in the way instructors teach this course, and what problems they face while teaching the course with an assumption that all students had no prior training in project management. What small changes are necessary to bring out the best in students by choosing selective topics that are good to teach over the the ones that are necessary to teach.

\section{The Nitobe school program}

Hokkaido University (founded 1876) is a leading national research university in Japan and entering the $150^{\text {th }}$ anniversary soon. It has been included in the "Top Global University" project by the Japanese Ministry of Education, Culture, Sports, and Technology (MEXT) as an institute that has the potential to be included in the top global 100 institutes in the world in coming years. To commemorate the anniversary, a future strategy is planned out to produce top-class graduates that possess sound judgment with deep insight and have the ability to work in an inter-disciplinary, multicultural environment, thereby playing a leading role in 


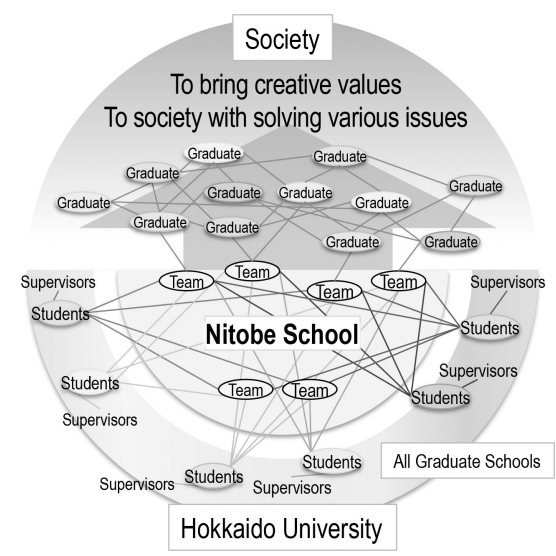

Figure 1: Socio-Academic Ecosystem connecting Hokkaido University to the international society and disciplines.

the development of global society. In 2015, the Nitobe School (now called Nitobe College*) came into existence to fulfill this ambitious goal. The aim of this special trans-graduate school is to enhance student learning abilities by imparting practical knowledge and training on the necessary soft skills and competencies. These skills will prepare them for the future world problems that are challenging and at the same time contribute to the society with a reflective and leadership-oriented mindset. The aim and design of the program have been previously described in detail in the study conducted by Yamanaka et.al [17, 18] (Figure 1). The final goal is to create a socio-academic ecosystem connecting Hokkaido University to the international society and disciplines[19].

\begin{tabular}{ll}
\hline & \multicolumn{1}{c}{ Course Schedule Description } \\
\hline Time & Details \\
\hline March- April & Orientation for Prospective Students \\
\hline May - June & Spring Term Basics of Team-based Learning (Compulsory) \\
\hline June - August & Summer Term Practice of Team-based Learning \\
\hline Sep.- Nov. & Fall Term Problem Solving \\
\hline Nov. - Jan. & Winter Term Problem Finding \\
\hline
\end{tabular}

Table 1: Nitobe School Course Schedule

The Nitobe School offers a learning environment which is truly a "microcosm of international society" where graduate students from different field of studies and with diverse cultural values and ethnic backgrounds collaborate, and create shared knowledge solution to urgent global issues. By so doing, the students develop various skills for productive, interdisciplinary, intersectional, and intercultural collaboration. More concretely, the program trains the students as professionals with the following competencies.

- The competency to develop and expand the already acquired professional competency in response to problems (ability for personal development)

*https://nitobe-college.academic.hokudai.ac.jp/ 
- The competency to consolidate individual competency into team competency and lead the team in problem-solving (team organization and management skills)

- The competency to create social value and change society (knowledge sharing and application capacity)

The style of teaching at Nitobe School is primarily Problem Based Learning (PBL) and Team-Based Learning (TBL) in an active learning classroom [17, 20, 21, 22]. The study in this paper focuses on the summer term course titled: "Practice of Team-Based Learning". Prior to the summer course, students are given basic core training on the principle and goals of Nitobe School " $3+1$ competencies", the essential "know-how" of the TBL and PBL group-based collaborative activities, facilitation rules, team building, team discussion, time management, creating and dissipating ideas, giving individual and group presentations, and methods for communication [23, 18]. Most of these skills prepare the student to do effective team discussions and understand the ethics of the TBL. Apart from the basic training, students learn to use engagement tools for effective TBL, such as, using sticky notes for generating knowledge maps, tablet computers for data search, poster presentations, multimedia presentations, and whiteboard discussions.

\section{Outline of the Summer Term: Practice of Team Based Learn- ing}

The summer course on titled "Practice of TBL", is focused on the project management training. The students need to participate in collaborative projects with peers and partners with different intellectual concerns and expertise and gain essential foundation in project management tools. The students are trained through collaborative team projects and the knowledge acquired during the spring term. At the end of the course the students would-

- Understand the importance of project management.

- Acquire basic knowledge and skills on project management and apply them practically in projects, including their own research projects at respective graduate schools.

- Understand the importance of team-based projects and teamwork to accomplish given goals in the time frame using the knowledge acquired during the spring term.

The course consist of 8 sessions of 3 hours of lectures (total of two credits) offered a week thrice. The detailed course schedule is given in Table 2.

\subsection{Project Management Learning}

As stated earlier, the class structure in the Nitobe School are of PBL style with focus on the team collaborative work. The PBL framework generally consists of the following characteristics (1) learning is student centered, (2) learning process occurs in small groups, (3) role of teachers are as guides and facilitators, (4) problems form the organizing focus and stimulus for learning, (5) problems are a vehicle for the development of problem-solving skills and (6) new information is acquired through self-directed learning [24]. As part of our PBL approach, students had to engage in actual project or problem. While problem exposed learning is common in the PBL approaches, there is hardly any training on project management tools that the student learn. We wanted to change this by bringing in particular PM tools into the PBL framework and create a hybrid learning framework to increase the 
Course Description

\begin{tabular}{ll} 
Week & Goals \\
\hline $\begin{array}{l}\text { 1. Week 1:Course Orientation } \\
\text { Review of learning out- } \\
\text { come from the spring term } \\
\text { - Course Orientation: }\end{array}$ & $\begin{array}{l}\text { - The goal and objectives of the course, class formats and basic rules, eval- } \\
\text { uation/grading policies, academic calendar and class schedule, etc., are ex- } \\
\text { plained. }\end{array}$ \\
- Spring Term Review: & $\begin{array}{l}\text { - Student set their learning goal for this term and discuss how that goal can be } \\
\text { achieved based on the review of the learning outcomes from the spring term. }\end{array}$ \\
2. Week 2-7: Project Management Basics and Practice \\
PM 2-7 \\
$\begin{array}{l}\text { understand and share basic conceptions, or "lingua franca," regarding project } \\
\text { management, such as prototyping, gantt chart, WBS, and risk management, } \\
\text { through guidance lectures and group discussions }\end{array}$ \\
- Based on the knowledge above, students work in group on practical ex- \\
ercises to make a simple project on a given topic or case study assigned by \\
lecturers (as required by clients). In doing so, they are to record steps in the \\
process of designing the project, and in concluding, they present the project \\
to the clients following the consequence of stereotyping. \\
- Students have post-project reflections through group and class discussions, \\
in which they compare the process and outcomes of their project with one \\
another. Based on the reflections, students make a study plan for the fall and \\
winter terms.
\end{tabular}

Table 2: Project Management Course Schedule

learning exposure. We also want to reflect on the outcomes of such teachings and course work for future improvements. The framework is depicted in Figure 2.

At the course orientation, students are divided into teams (5-6 students per group) with a total of 4-5 groups. The students are briefed about their respective teams and ice breaking activities are performed for team bonding. The student teams are to undertake a project from scratch and develop the project over the course and present their respective findings at the end of the course using audio-visual group presentations. The groups are also required to submit a project report at the end of the course with individual contribution mentioned and the lessons learned from the team project undertaken. A common project is given to all the groups and each team has to brainstorm ideas and come up with strategies to complete the project. The students should use PBL and PM tools that are taught during each session to support their project work.

The students are introduced the necessary PM tools at every step of the course that are carefully selected and includes topics such as: project proposal and charter, scope and deliverables, resource management, stakeholder analysis, task and time management, risk management, cost analysis, planning, and scheduling. Most of the skills are taught to the students during the initial three weeks at the beginning of the course. The instructors would reiterate core concepts and methods of PM tools over different lectures to make students 


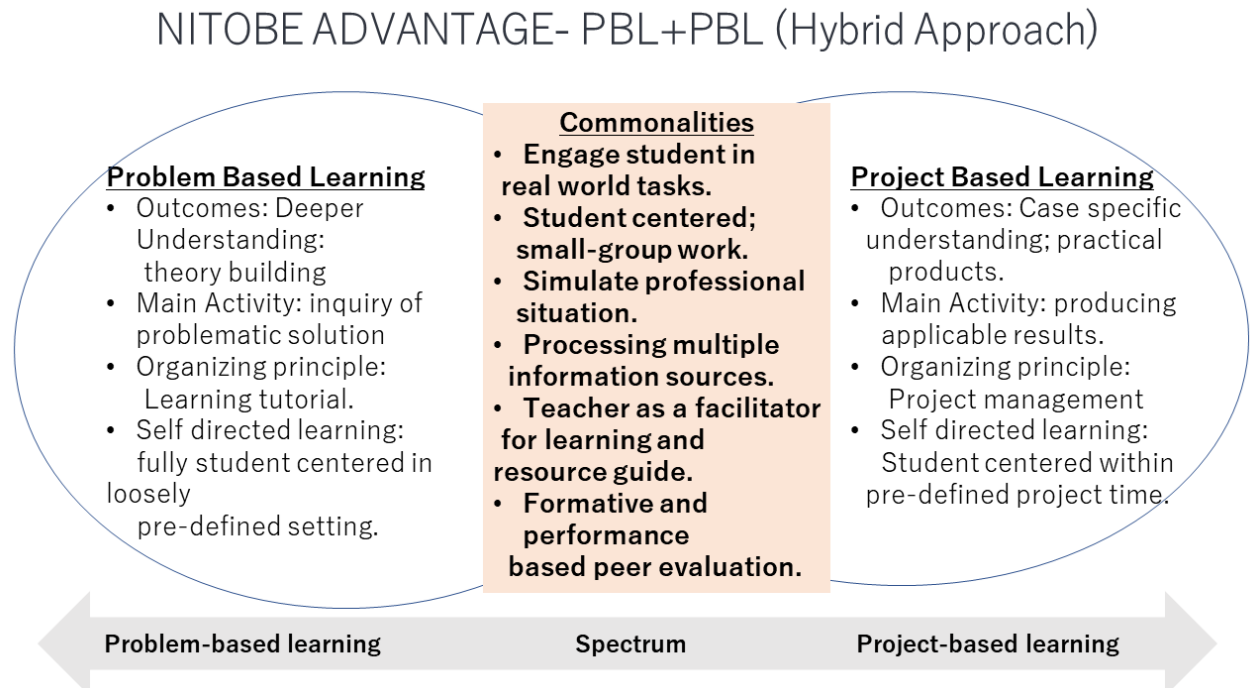

Figure 2: Framework of Nitobe hybrid approach for Project-Problem based learning

more comfortable with topics that are hard to understand. Overall most of the mentioned topics are successfully covered during the course. The details of each PM skill delivered during the lectures will not be discussed in this study and can be found in the PMBOK[13] that was used a reference manual during the course. The students are able to apply the methods to their project as they progress through the course and make progress towards completion. An important point to note is that, student would still use the TBL and PBL tools for their reasoning and by learning the new PM tools, they are able to put forward the ideas more effectively. Concretely the following PM abilities are the target for the student to learn:

- Documenting various project ideas.

- Identify and analyze project selection methods.

- Initiate with stakeholders, stakeholder mapping after selecting project.

- Reasoning and critical thinking for project based on selection criteria.

- Identify and create reasonable project scope.

- Identify and create reasonable project outcomes.

- Identify and create reasonable schedule.

- Summarize, analysis and evaluate project charter and initiate project planning.

- Control project execution and changes.

- Communicate with stakeholders.

- Identify risk and risk management.

- Evaluate project outcomes.

- Work Breakdown Structure (WBS).

- Project management/ leadership process.

- Identify growth/improvement during and after project. 
During the project phase, the students get complete support from the facilitators and instructors at each step of the way and are able to understand the concepts of PM and work towards finishing the project. Throughout the course, the students constantly share with the instructors their thought process, and in return receive critical feedback to improve their project. The student groups also learn from the other teams that are working on similar themed project by communicating bottlenecks and learn from the shared knowledge to overcome such hurdles. Student in the teams are encouraged to communicate as much as possible to overcome their anxiety about some of the techniques or the "jargons" of the PM documentation. The group interaction allow the students to express themselves and simplifying such jargons of the PM glossary with the help from facilitators[25, 26]. Team discussions develops student's leadership and coordination skills, communication, presentation ideas, and argumentation, which are critical skill essential during discussion. We enhanced such learning by providing necessary environment for interaction, nurturing individual and group motivations, and learning by doing approach to help the teams reach their learning goals. It has also been proved that learning environment plays and important role in promotion interaction between individuals[27]. Teams that struggle initially generally tend to progress quickly by communicating problems and through interaction with other student teams. The shared opinions and free flowing ideas improve their design ideas during the quick presentation seminar that we conduct at the end of each class. In these small presentation sessions each team learns about other team's progress and suggest ideas to improve their design. A system to support the student interaction outside the class hours is also provided by using the Nitobe e-portfolio where the members can continue to discuss and work on finishing the project online. The e-portfolio is supervised by the instructors who monitor the groups and can also interact with students after the class supporting their discussions [28].

\section{The Survey}

The students were asked questions that are broadly grouped into two main categories- general knowledge about project management techniques and learning outcomes, and attitude towards project management. Two questionnaire were collected during the course. One paper-based questionnaire was distributed in the second week, and another one right after the final class of the course. The questions in the survey mainly consisted about student's general understanding of the project management theory and whether the student had any prior experience of project management. Other questions mainly consisted about their

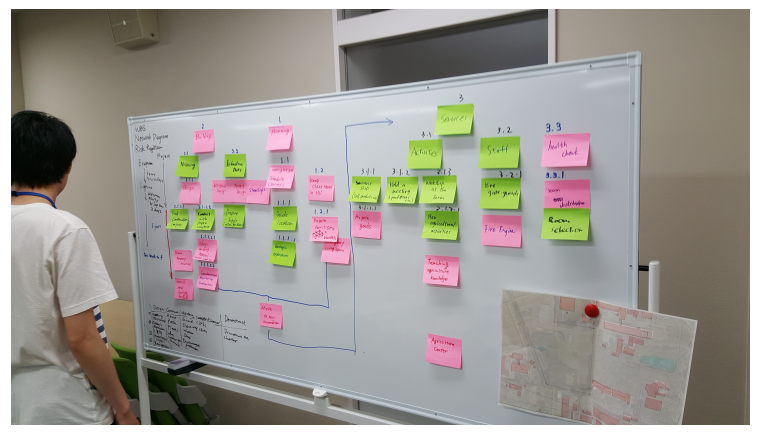

Figure 3: Student team working out the WBS analysis during one of the classes 
learning experiences from the course. The learning outcomes were broadly grouped into critical thinking, problem-solving, communication skills, interpersonal skill, time management, and self-learning. The key factors that we were aiming to learn from the questionnaire were:

1. Long term utility of the skills learned in the classroom and appreciation of the PM skills to enhance student's career.

2. Know the PM vocabulary and be able to communicate effectively in their respective careers.

3. Learning a deeper understanding of the project details and its related activities.

4. Application of PM tools and skills in a wide range of activities.

5. Using PBL and TBL approach to learning PM tools.

6. Group work appreciation and team building importance.

7. Leadership and self-motivation.

The project management knowledge questions constituted eight unique knowledge topics as described by the project management institute (PMI) in the project management book of knowledge (PMBOK). These unique topics were selected carefully considering the time constraints for the course. They are mainly: stakeholder analysis, project scopes, deliverables and milestones, network diagram, project scheduling, cost analysis, risk management, and work breakdown structure (WBS).

\section{Questionnaire Evaluation}

\subsection{Data Analysis}

We used a five point Likert psychometric scale for the research questionnaire and survey analysis. It is the most widely used method to scaling responses in survey researches and often uses rating scale. The scale in this research ranges from one (1) which represents 'very low' to five (5), representing 'very high'. The questions were easy to read and understand. The students were comfortable with the scale and wording of the questions given to them. A total of $61(N)$ students participated in the survey (male $=38$ and female=23). The students participated from 18 different graduate schools and included students from both master course and doctoral course. The classes were international and students from 13 different nationalities participated in the course.

\subsection{Survey results}

\subsubsection{Project Management Background}

The first set of questions queried the previous background of students for project management knowledge, importance of project management and importance of others in the team to know about project management. 


\begin{tabular}{|c|c|c|c|c|c|}
\hline & Q.1 & & Q.2 & & Q.3 \\
\hline Valid & 61 & Valid & 61 & Valid & 61 \\
\hline Missing & 0 & Missing & 0 & Missing & 0 \\
\hline Mean & 4.689 & Mean & 1.295 & Mean & 4.770 \\
\hline Std. Error of Mean & 0.060 & Std. Error of Mean & 0.071 & Std. Error of Mean & 0.054 \\
\hline Median & 5.000 & Median & 1.000 & Median & 5.000 \\
\hline Std. Deviation & 0.467 & Std. Deviation & 0.558 & Std. Deviation & 0.424 \\
\hline
\end{tabular}

Table 3: Descriptive Statistics for Q.1, Q.2, and Q.3.

\begin{tabular}{lrrrr}
\hline Q.1 & Frequency & Percent & Valid Percent & Cumulative Percent \\
\hline 4 & 19 & 31.148 & 31.148 & 31.148 \\
5 & 42 & 68.852 & 68.852 & 100.000 \\
Missing & 0 & 0.000 & & \\
Total & 61 & 100.000 & & \\
\hline \hline Q.2 & Frequency & Percent & Valid Percent & Cumulative Percent \\
\hline 1 & 46 & 75.410 & 75.410 & 75.410 \\
2 & 12 & 19.672 & 19.672 & 95.082 \\
3 & 3 & 4.918 & 4.918 & 100.000 \\
Missing & 0 & 0.000 & & \\
Total & 61 & 100.000 & & 100.000 \\
\hline \hline Q.3 & Frequency & Percent & Valid Percent & Cumulative Percent \\
\hline 4 & 14 & 22.951 & 22.951 & \\
5 & 47 & 77.049 & 77.049 & \\
Missing & 0 & 0.000 & & \\
Total & 61 & 100.000 & & \\
\hline
\end{tabular}

Table 4: Frequencies for Q.1, Q.2, and Q.3.

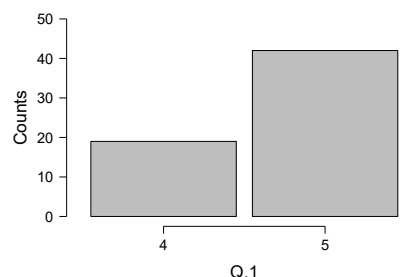

(a) Q.1

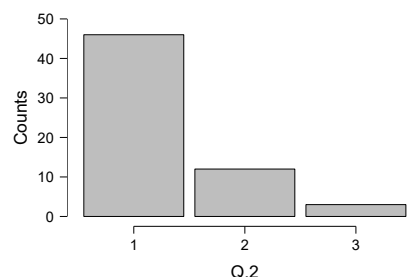

(b) Q.2

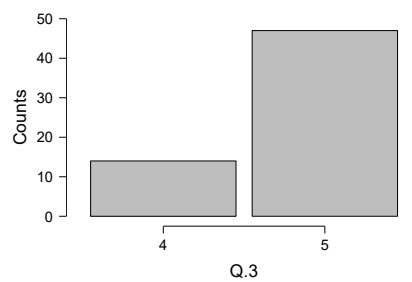

(c) Q.3

Figure 4: Freqency responce for Q.1, Q.2, and Q.3

Q.1 Importance of project management.

Q.2 Previous background of project management.

Q.3 Importance of others in the team to know project management. 
From Table 2, it is evident that most of the student's who were enrolled in the course felt that project management is an important tool to learn. Almost all the students had no prior background in project management (Q.2) with $(M=1.295)$ which accounts between low to very low on the rating scale. On question about the importance of project management for the team member, the $(M=4.77)$ (very high) suggests that most students feel that it is an important factor. Table 4, shows the frequencies of responses for Q.1 to Q.3. Figure 4 shows the responses in bar chart.

\subsubsection{Project Management Knowledge}

We had seven questions pertaining to project management foundation. The modules in the first three weeks covered these basic essential project management unique knowledge that the students would use to eventually plan the final project. Based on the responses we performed the descriptive statistical analysis for each of the unique concepts and evaluated the results based on the student's understanding. The questions were:

Q.4 Identify stakeholders in the project and carry out stakeholder analysis.

Q.5 Identify requirements for the scope from the project charter and create scope statement from the requirements (scope analysis).

Q.6 Developing network of project activities for viewing tasks, dependencies and critical path of the project.

\begin{tabular}{|c|c|c|c|c|c|}
\hline & Q.4 & & Q.5 & & Q.6 \\
\hline Valid & 61 & Valid & 61 & Valid & 61 \\
\hline Missing & 0 & Missing & 0 & Missing & 0 \\
\hline Mean & 4.016 & Mean & 3.902 & Mean & 3.754 \\
\hline Std. Error of Mean & 0.083 & Std. Error of Mean & 0.096 & Std. Error of Mean & 0.083 \\
\hline Median & 4.000 & Median & 4.000 & Median & 4.000 \\
\hline Std. Deviation & 0.645 & Std. Deviation & 0.746 & Std. Deviation & 0.650 \\
\hline Variance & 0.416 & Variance & 0.557 & Variance & 0.422 \\
\hline Minimum & 2.000 & Minimum & 2.000 & Minimum & 2.000 \\
\hline \multirow[t]{2}{*}{ Maximum } & 5.000 & Maximum & 5.000 & Maximum & 5.000 \\
\hline & Q.7 & & Q.8 & & Q.9 \\
\hline Valid & 61 & Valid & 61 & Valid & 61 \\
\hline Missing & 0 & Missing & 0 & Missing & 0 \\
\hline Mean & 3.918 & Mean & 3.951 & Mean & 4.033 \\
\hline Std. Error of Mean & 0.088 & Std. Error of Mean & 0.079 & Std. Error of Mean & 0.084 \\
\hline Median & 4.000 & Median & 4.000 & Median & 4.000 \\
\hline Std. Deviation & 0.690 & Std. Deviation & 0.617 & Std. Deviation & 0.657 \\
\hline Variance & 0.477 & Variance & 0.381 & Variance & 0.432 \\
\hline Minimum & 2.000 & Minimum & 2.000 & Minimum & 2.000 \\
\hline \multirow[t]{11}{*}{ Maximum } & 5.000 & Maximum & 5.000 & Maximum & 5.000 \\
\hline & & & Q.10. & & \\
\hline & & Valid & 61 & & \\
\hline & & Missing & 0 & & \\
\hline & & Mean & 3.754 & & \\
\hline & & Std. Error of Mean & 0.109 & & \\
\hline & & Median & 4.000 & & \\
\hline & & Std. Deviation & 0.850 & & \\
\hline & & Variance & 0.722 & & \\
\hline & & Minimum & 1.000 & & \\
\hline & & Maximum & 5.000 & & \\
\hline
\end{tabular}

Table 5: Descriptive Statistics 


\begin{tabular}{|c|c|c|c|c|}
\hline Q.4 & Frequency & Percent & Valid Percent & Cumulative Percent \\
\hline 2 & 1 & 1.639 & 1.639 & 1.639 \\
\hline 3 & 9 & 14.754 & 14.754 & 16.393 \\
\hline 4 & 39 & 63.934 & 63.934 & 80.328 \\
\hline 5 & 12 & 19.672 & 19.672 & 100.000 \\
\hline Missing & 0 & 0.000 & & \\
\hline Total & 61 & 100.000 & & \\
\hline Q.5 & Frequency & Percent & Valid Percent & Cumulative Percent \\
\hline 2 & 4 & 6.557 & 6.557 & 6.557 \\
\hline 3 & 8 & 13.115 & 13.115 & 19.672 \\
\hline 4 & 39 & 63.934 & 63.934 & 83.607 \\
\hline 5 & 10 & 16.393 & 16.393 & 100.000 \\
\hline Missing & 0 & 0.000 & & \\
\hline Total & 61 & 100.000 & & \\
\hline Q.6 & Frequency & Percent & Valid Percent & Cumulative Percent \\
\hline 2 & 2 & 3.279 & 3.279 & 3.279 \\
\hline 3 & 16 & 26.230 & 26.230 & 29.508 \\
\hline 4 & 38 & 62.295 & 62.295 & 91.803 \\
\hline 5 & 5 & 8.197 & 8.197 & 100.000 \\
\hline Missing & 0 & 0.000 & & \\
\hline Total & 61 & 100.000 & & \\
\hline Q.7 & Frequency & Percent & Valid Percent & Cumulative Percent \\
\hline 2 & 2 & 3.279 & 3.279 & 3.279 \\
\hline 3 & 11 & 18.033 & 18.033 & 21.311 \\
\hline 4 & 38 & 62.295 & 62.295 & 83.607 \\
\hline 5 & 10 & 16.393 & 16.393 & 100.000 \\
\hline Missing & 0 & 0.000 & & \\
\hline Total & 61 & 100.000 & & \\
\hline Q.8 & Frequency & Percent & Valid Percent & Cumulative Percent \\
\hline 2 & 1 & 1.639 & 1.639 & 1.639 \\
\hline 3 & 10 & 16.393 & 16.393 & 18.033 \\
\hline 4 & 41 & 67.213 & 67.213 & 85.246 \\
\hline 5 & 9 & 14.754 & 14.754 & 100.000 \\
\hline Missing & 0 & 0.000 & & \\
\hline Total & 61 & 100.000 & & \\
\hline Q.9 & Frequency & Percent & Valid Percent & Cumulative Percent \\
\hline 2 & 1 & 1.639 & 1.639 & 1.639 \\
\hline 3 & 9 & 14.754 & 14.754 & 16.393 \\
\hline 4 & 38 & 62.295 & 62.295 & 78.689 \\
\hline 5 & 13 & 21.311 & 21.311 & 100.000 \\
\hline Missing & 0 & 0.000 & & \\
\hline Total & 61 & 100.000 & & \\
\hline Q.10. & Frequency & Percent & Valid Percent & Cumulative Percent \\
\hline 1 & 1 & 1.639 & 1.639 & 1.639 \\
\hline 2 & 4 & 6.557 & 6.557 & 8.197 \\
\hline 3 & 13 & 21.311 & 21.311 & 29.508 \\
\hline 4 & 34 & 55.738 & 55.738 & 85.246 \\
\hline 5 & 9 & 14.754 & 14.754 & 100.000 \\
\hline Missing & 0 & 0.000 & & \\
\hline Total & 61 & 100.000 & & \\
\hline
\end{tabular}

Table 6: Frequencies for Q.4 
Q.7 Creating risk register and risk response plans and perform risk management for project tasks.

Q.8 Developing a project schedule to accommodate project constraints (project scheduling).

Q.9 Creating a work breakdown structure (WBS) from the requirements.

Q.10 Estimate time and cost by doing cost analysis and perform decomposition and bottomup estimation.

From the questionnaire responses, it can be concluded that most students were able to grasp the basic knowledge of the project management concepts that were taken up during the class. For Q.4 - Stakeholder analysis $(M=4.02, S D=0.65)$, Q.5 - Scope analysis $(M=$ $3.90, S D=0.75)$, Q.6 - Network diagram and critical path analysis $(M=3.76, S D=0.66)$, Q.7 - Risk Management $(M=3.92, S D=0.70)$, Q.8 - Project scheduling $(M=3.96, S D=$ $0.62)$, Q.9 - WBS $(M=4.03, S D=0.66)$, and Q.10 - Cost analysis $(M=3.75, S D=0.85)$ respectively the mean and standard deviations are presented. From these results, we can conclude that except Q.6 (Network diagram/critical path analysis) and Q.10 (Cost analysis), the student rated their learning as 'high'. One reason for the low mean values for Q. 6 and Q. 10 could attribute to the complexity of these concepts which in our opinion would require more time to grasp. This was also evident from some of the post-course comments that we received, where student stated that "It was hard to understand the process of making network diagram in the given time frame. More time should be given to understand such difficult topics by the teachers".

\subsubsection{Student attitude and learning outcomes}

For evaluating the student's learning outcomes in terms of their attitude and soft skills that the student acquired after the course, we did a pre- and post-course survey on questions pertaining to the improvement in their critical thinking, problem solving skills, communication, interpersonal skills such as leadership and team management and self learning. We performed a paired samples t-test or dependent samples t-test on these attributes and compared the pre-post results.

1. Critical thinking- We measured student's learning outcomes based on how challenged they felt before and after the course, ability to make judgment about different perspectives, ability to evaluate long-term and short-term alternative solutions, and their ability to generate and incorporate new ideas.

\begin{tabular}{rrrrrrrrrrr}
\hline & & & & & & & & \multicolumn{2}{l}{$95 \%$ CI for Mean Difference } \\
& & $\mathrm{t}$ & $\mathrm{df}$ & $\mathrm{p}$ & Mean Diff. & SE Diff. & Lower & Upper & Cohen's d \\
\hline Pre & - & Post & -18.719 & 60 & $<.001$ & -1.119 & 0.060 & -1.238 & -0.999 & -2.397 \\
\hline
\end{tabular}

Note. Student's t-test.

Table 7: Paired Samples T-Test - Critical thinking 
Table 8: Descriptives- Critical Thinking

\begin{tabular}{lrrrr}
\hline & N & Mean & SD & SE \\
\hline Pre & 61 & 3.086 & 0.456 & 0.058 \\
Post & 61 & 4.205 & 0.404 & 0.052 \\
\hline
\end{tabular}

Table 9: Test of Normality (Shapiro-Wilk)

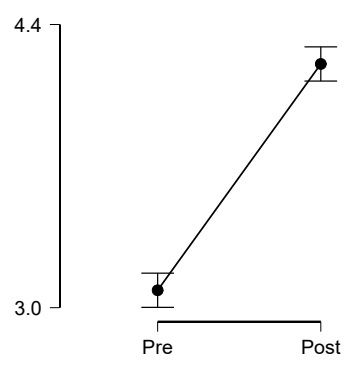

\begin{tabular}{|c|c|c|c|c|}
\hline & & & W & $\mathrm{p}$ \\
\hline Pre & . & Post & 0.966 & 0.086 \\
\hline
\end{tabular}

Figure 5: Descriptive plot of pre-post survey

2. Problem solving- Through the survey we tried to measure improvement in student's problem solving ability after completing the course. Mainly our target was the attitude towards approaching the problem by finding alternative methods rather than relying on same approach every time. Ability to understand the hidden patterns among different elements in a problem such that they are able to uncover such dimensions to solve a particular problem. And finally, their approaches towards solving a problem as an individual and when working in a team.

\begin{tabular}{|c|c|c|c|c|c|c|c|c|c|}
\hline & & \multirow[b]{2}{*}{$\mathrm{t}$} & \multirow[b]{2}{*}{ df } & \multirow[b]{2}{*}{$\mathrm{p}$} & \multirow[b]{2}{*}{ Mean Diff. } & \multirow[b]{2}{*}{ SE Diff. } & \multicolumn{2}{|c|}{ 95\% CI for Mean Difference } & \multirow[b]{2}{*}{ Cohen's d } \\
\hline & & & & & & & Lower & Upper & \\
\hline Pre & - Post & -19.441 & 60 & $<.001$ & -1.170 & 0.060 & -1.291 & -1.050 & -2.489 \\
\hline
\end{tabular}

Note. Student's t-test.

Table 10: Paired Samples T-Test- Problem Solving

Table 11: Descriptives- Problem Solving

\begin{tabular}{lrrrr}
\hline & N & Mean & SD & SE \\
\hline Pre & 61 & 2.993 & 0.495 & 0.063 \\
Post & 61 & 4.164 & 0.401 & 0.051 \\
\hline
\end{tabular}

Table 12: Test of Normality (Shapiro-Wilk)

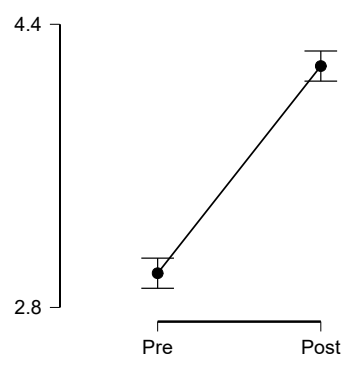

\begin{tabular}{|c|c|c|c|c|}
\hline & & & W & $\mathrm{p}$ \\
\hline Pre & - & Post & 0.951 & 0.016 \\
\hline
\end{tabular}

Figure 6: Descriptive plot of pre-post survey.

3. Communication- It is evident from many studies that communication is the key for a successful project. Since the educational framework at Nitobe involves TBL and PBL approaches, it was important to measure how much communication skills of the student improved from the course. Another important element we wanted to test was the student's ability to dissipate their ideas and communicate with team members in a multi-lingual and multi-cultural team environment. 


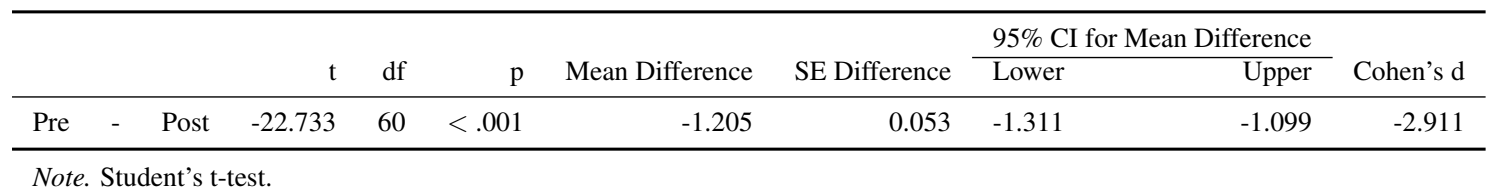

Table 13: Paired Samples T-Test- Communication

Table 14: Descriptives- Communication

\begin{tabular}{lrrrr}
\hline & N & Mean & SD & SE \\
\hline Pre & 61 & 2.936 & 0.563 & 0.072 \\
Post & 61 & 4.141 & 0.468 & 0.060
\end{tabular}

Table 15: Test of Normality (Shapiro-Wilk)

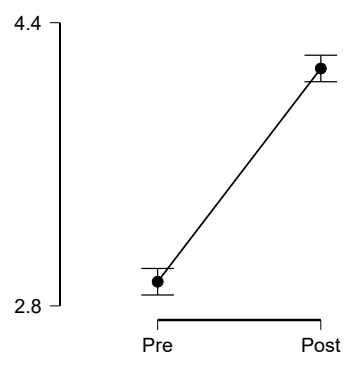

\begin{tabular}{|c|c|c|c|c|}
\hline & & & W & $\mathrm{p}$ \\
\hline Pre & - & Post & 0.974 & 0.211 \\
\hline
\end{tabular}

Figure 7: Descriptive plot of pre-post survey.

4. Interpersonal skills - Attributes such as being a good team member, leadership, commitment towards team's success and ability to adapt and be flexible to different roles were tested and how much improvement the course brought to this element of their personality.

\begin{tabular}{|c|c|c|c|c|c|c|c|c|c|c|}
\hline & & & \multirow[b]{2}{*}{$\mathrm{t}$} & \multirow[b]{2}{*}{$\mathrm{df}$} & \multirow[b]{2}{*}{$\mathrm{p}$} & \multirow[b]{2}{*}{ Mean Diff. } & \multirow[b]{2}{*}{ SE Diff. } & \multicolumn{2}{|c|}{ 95\% CI for Mean Difference } & \multirow[b]{2}{*}{ Cohen's d } \\
\hline & & & & & & & & Lower & Upper & \\
\hline Pre & - & Post & -19.427 & 60 & $<.001$ & -1.145 & 0.059 & -1.263 & -1.028 & -2.487 \\
\hline
\end{tabular}

Note. Student's t-test.

Table 16: Paired Samples T-Test- Interpersonal skills

Table 17: Descriptives- Interpersonal skills

\begin{tabular}{lrrrr}
\hline & N & Mean & SD & SE \\
\hline Pre & 61 & 2.973 & 0.457 & 0.058 \\
Post & 61 & 4.119 & 0.389 & 0.050 \\
\hline
\end{tabular}

Table 18: Test of Normality (Shapiro-Wilk)

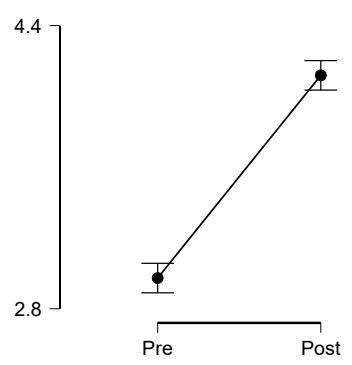

\begin{tabular}{|c|c|c|c|c|}
\hline & & & W & $\mathrm{p}$ \\
\hline Pre & - & Post & 0.978 & 0.346 \\
\hline
\end{tabular}

Figure 8: Descriptive plot of pre-post survey.

5. Time management and self learning - The final attribute that we tested in this research was towards improvement in managing tasks and time in a project, their ability to do multitasking and how much confident they felt after the course. 


\begin{tabular}{|c|c|c|c|c|c|c|c|c|c|}
\hline & & \multirow[b]{2}{*}{$\mathrm{t}$} & \multirow[b]{2}{*}{$\mathrm{df}$} & \multirow[b]{2}{*}{$\mathrm{p}$} & \multirow[b]{2}{*}{ Mean Diff. } & \multirow[b]{2}{*}{ SE Diff. } & \multicolumn{2}{|c|}{ 95\% CI for Mean Difference } & \multirow[b]{2}{*}{ Cohen's d } \\
\hline & & & & & & & Lower & Upper & \\
\hline Pre & - Post & -18.155 & 60 & $<.001$ & -1.230 & 0.068 & -1.365 & -1.094 & -2.324 \\
\hline
\end{tabular}

Table 19: Paired Samples T-Test- Time management and Self-learning

Table 20: Descriptives- Time Management and self-learning

\begin{tabular}{lrrrr}
\hline & N & Mean & SD & SE \\
\hline Pre & 61 & 2.977 & 0.518 & 0.066 \\
Post & 61 & 4.207 & 0.397 & 0.051 \\
\hline
\end{tabular}

Table 21: Test of Normality (Shapiro-Wilk)

\begin{tabular}{|c|c|c|c|c|}
\hline & & & W & $\mathrm{p}$ \\
\hline Pre & - & Post & 0.929 & 0.002 \\
\hline
\end{tabular}

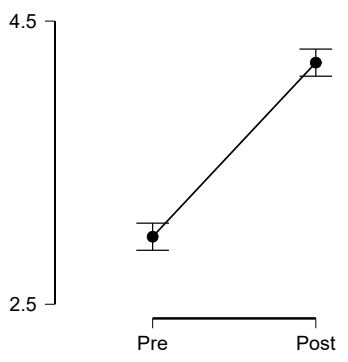

Figure 9: Descriptive plot of pre-post survey.

\subsection{Sample Observations}

From the above study, we concluded different hypothesis about the five parameters. In this paragraph we provide the description of our observations for all the parameters together to keep the uniformity.

To test the hypothesis that the pre-course parameters [(Critical thinking - $M=3.09, S D=$ $0.46)$, Problem Solving $(M=3.00, S D=0.95)$, Communication $(M=2.93, S D=0.56)$, Interpersonal skills $(M=2.98, S D=0.46)$, and Time management/self-learning $(M=2.98, S D=$ $0.52)$, and post-course parameters [(Critical thinking $-M=4.20, S D=0.40)$, Problem Solving $(M=4.16, S D=0.40)$, Communication $(M=4.14, S D=0.47)$, Interpersonal skills $(M=4.12, S D=0.39)$, and Time management/self-learning $(M=4.20, S D=0.38)]$ were equal, the dependent samples t-test was performed. Prior to conducting the analysis, the assumptions of normally distributed differences scores was examined. The normality check was performed that is evident from the Shapiro-Wilk test values as given in Table. 9, Table.12, Table. 15, Table. 18 and Table. 21 respectively, which is less than the maximum allowable values for a t-test for all cases. The null hypothesis of equal mean scores was rejected, [(Critial thinking $-t=-18.72, p<.001)$, Problem Solving $(t=-19.44, p<.001)$, Communication $(t=-22.73, p<.001)$, Interpersonal skills $(t=-19.43, p<.001)$, and Time management/self-learning $(t=-18.15, p<.001)]$. Thus the post-course evaluation mean was statistically significantly higher than the pre-course mean. Cohen's $d$ was estimated at $[($ Critial thinking $-d=-2.40)$, Problem Solving $(d=-2.49)$, Communication $(d=-2.91)$, Interpersonal skills $(d=-2.49)$, and Time management/self-learning $(d=-2.32)$ ] respectively, which is a large effect based on the study by Cohen[29]. A graphical representation of the means and adjusted 95\% confidence intervals [30] are displayed in Figure 5, Figure 6, Figure 7, Figure 8, and Figure 9 respectively. The results suggest a significant improvement in the learning outcomes on the study-parameters and it proves that the outcome of the study is successful. Therefore we can conclude from the study that our methods were effective in bringing positive change in student's attitude and their soft skills. 


\subsection{Other Reflections}

The post- course questionnaire also asked students about their satisfaction level with the course. All students (100\%) replied that the course was relevant for their future career. $98 \%$ of the students stated that, learning PM skills is helpful for their current/future project. As to which PM skill the student found most useful, majority of the student reported product life cycle, project scheduling, and risk management (in order). Some quotes from the student illustrate this notion.

"Project Scheduling was difficult, but very interesting to do. I plan to use it in my study from now on."

$91 \%$ of the student replied that communication within the team is the most important factor for successful project completion. $82 \%$ of the students felt that their leadership skills have improved after the course. While $91 \%$ replied that they have become an effective team member. $88 \%$ of the student rated the course as "Excellent". Some voices of students after the course are quoted below:

"I really like the subjects in this course. Not only providing English speaking environment but also a very comfortable place to learn project management in a team. I have learned a lot from this course."

\subsection{Instructor Reflections}

Teaching this course has given us very important lessons that will be useful for it's improvement in the future. Firstly, we truly believe that PM training should start as early as possible in student life. Students enrolled in schools and universities are at the best age of learning and taking an early leap will provide immense confidence and improve their employability. At the graduate level, PM training makes much more sense since majority of the graduate students undertake research projects for their graduation degree. For students enrolled in doctoral program, knowing how to manage their dissertation and research progress efficiently can ease the peer pressure of graduating. Learning the PM techniques, will only accelerate their research work and teach them to have better management of time and resources. After this particular course, students at the Nitobe college will move to the next course on 'Problem solving' and 'Problem finding', which will further strengthen their concepts on project based learning. Many students stated after the course that doing practical projects would be more useful rather than just planning the project.

"I will be more happy if we not only plan the project but also have the time to implement it in reality, may be we can start from a small prospect."

This is one area where more work has to be done. Another way to solve this problem could be to encourage students to take internship jobs in companies and apply the PM skills they have learned for the project. This is one area that we still have to put more effort on and we believe that over the years some solution will be found. Some students also complained that not all team members were willing to put efforts into the project and this slowed their progress during the project planning. But positively, they also stated that, this allowed them to switch roles between team members and be more responsible. A key factor to this course that we found very interesting was that student understood that communication is the key to successful project. Many teams were constantly discussing and communicating with 
the instructors and facilitators going back to the project charter and improving their ideas. Mixing students of different background and specialty helped students learn the thinking process of such individuals and helped them bring combined creative ideas. Students also appreciated discussions with other teams and learning from their experiences. The cultural aspect of working in international teams also brought lots of creative thinking. From the facilitator point of view, interacting with students, we learned that it was important not to interfere too much within team discussions. Sometimes things become more complicated if the instructor or facilitator also put a new idea on the table and creates confusion due to the intimidating position. We found that only when the team discussion is stuck or not having a direction, intervention is positive. Reward and appreciation also plays an important role in project management training and we learned that teams perform better when they are rewarded for their efforts[31].

The current study is still in its preliminary stage as we are just one year into the introduction of the course. Nevertheless, we aim to continue this study for few more years and reflect performance indices for e ach y ear. Further studies on student's progress over the years is necessary to understand how effective PM learning is for their careers. The study can be further enhanced by tracking student's employment in the future and taking notes from what skills they still use in their work or what skills were helpful for their work environment or job employability. In future we also plan to bring experienced and successful program managers from the industries and put their views on the complexities of the real dynamic work environment and what PM skills student should focus on to overcome such complexities. We believe that such shared experiences will also encourage students to take entrepreneurship roles in the future. Moreover, we plan to bring new iterations to the learning and training from the feedback we have received during this course.

\section{Conclusion}

In this paper, we present a framework for an introductory project management course for graduate students. The survey results reveal that a good curriculum with quality training improves student's overall learning in all aspects including their soft skills. Pre- and postcourse survey results reflect this notion and this is statistically shown as research. From our studies we found that PM training at university and higher education has many benefits to student learning and will equip them with core skills for the market. Incorporating problem based learning and team based learning into the project management training can bring significant improvement in students creative learning and cognitive $t$ hinking. Such useful learning when integrated within the day to day project work must be reinforced through creative learning and thinking at an early stage of student life. In this work, we presented our experiences of implementing such an approach to training PM at a special trans-graduate school program and found such an approach to be very effective for improving student competencies.

\section{Acknowledgments}

Authors would like to thank faculties and students at Nitobe School, Hokkaido University for their cooperation and support for this study. We acknowledge the students support in filling the questionnaire and providing useful feedback for the improvement of this course. 


\section{References}

[1] W. G. Tierney, The responsive university: Restructuring for high performance. ERIC, 1998.

[2] M. M. Robles, "Executive perceptions of the top 10 soft skills needed in todays workplace," Business Communication Quarterly, vol. 75, no. 4, pp. 453-465, 2012.

[3] J. Raybould and V. Sheedy, "Are graduates equipped with the right skills in the employability stakes?," Industrial and commercial training, vol. 37, no. 5, pp. 259-263, 2005.

[4] R. Bridgstock, "The graduate attributes weve overlooked: Enhancing graduate employability through career management skills," Higher Education Research \& Development, vol. 28, no. 1, pp. 31-44, 2009.

[5] A. Longman and J. Mullins, "Project management: key tool for implementing strategy," Journal of business strategy, vol. 25, no. 5, pp. 54-60, 2004.

[6] H. Kerzner and H. R. Kerzner, Project management: a systems approach to planning, scheduling, and controlling. John Wiley \& Sons, 2017.

[7] I. Pant and B. Baroudi, "Project management education: The human skills imperative," International journal of project management, vol. 26, no. 2, pp. 124-128, 2008.

[8] T. J. Cooke-Davies and A. Arzymanow, "The maturity of project management in different industries: An investigation into variations between project management models," International Journal of Project Management, vol. 21, no. 6, pp. 471-478, 2003.

[9] J. Thomas and T. Mengel, "Preparing project managers to deal with complexityadvanced project management education," International journal of project management, vol. 26, no. 3, pp. 304-315, 2008.

[10] L. Pappas, "Special section the state of project management training," PM NETWORK, vol. 19, no. 8, p. 59, 2005.

[11] J. Ramazani and G. Jergeas, "Project managers and the journey from good to great: The benefits of investment in project management training and education," International Journal of Project Management, vol. 33, no. 1, pp. 41-52, 2015.

[12] A. A. Ravankar, S. Imai, and A. Ravankar, "Managing the project: The essential need for project management training and education in graduate schools," in Advanced Applied Informatics (IIAI-AAI), 2019 8th IIAI International Congress on, IEEE, 2019.

[13] A. Guide, "Project management body of knowledge (pmbok® guide)," in Project Management Institute, 2001.

[14] A. A. Ravankar, S. Imai, A. Ravankar, T. Kato, T. Takasuka, T. Tsuji, K. K. Shigetomi, and K. Saito, "Towards better problem finding and creativity in graduate school education," arXiv preprint arXiv:1807.02249, 2018.

[15] A. A. Ravankar, S. Imai, M. Shimamura, G. Chiba, and T. Takasuka, "Problem-based learning and problem finding among university graduate students," Journal of Higher Education and Lifelong Learning, vol. 24, pp. 9-20, 2017. 
[16] B. Egginton, "Realising the benefits of investment in project management training: Evidence supporting the need for a more strategic approach," International Journal of Managing Projects in Business, vol. 5, no. 3, pp. 508-527, 2012.

[17] Y. Yamanaka and M. Shimamura, "A trans-graduate-school education program awaking competencies to graduate students in research university: The concept of nitobe school program in hokkaido university," in Advanced Applied Informatics (IIAI-AAI), 2016 5th IIAI International Congress on, pp. 533-536, IEEE, 2016.

[18] Y. Yamanaka and M. Shimamura, "Establishing the brand-new trans-graduate education frame: Challenges of hokkaido university nitobe school program," International Journal of Institutional Research and Management, vol. 1, no. 2, pp. 37-53, 2017.

[19] M. Shimamura, Y. Kobayashi, and Y. Yamanaka, "What is the most suitable transferable skill test for the graduate school students in research university in japan? " the case report from the trial of" nitobe school program" in hokkaido university"," in Advanced Applied Informatics (IIAI-AAI), 2018 7th IIAI International Congress on, IEEE, 2018.

[20] S. Imai, A. A. Ravankar, M. Shimamura, T. E. Takasuka, G. Chiba, and Y. Yamanaka, "Discussion on a method of team-based-learning style lecture for graduate students in a research university," in Advanced Applied Informatics (IIAI-AAI), 2016 5th IIAI International Congress on, pp. 537-541, IEEE, 2016.

[21] M. Shimamura, S. Imai, A. A. Ravankar, and Y. Yamanaka, "How does the english ability of the student change through the postgraduate education? the case report of" nitobe school program" in hokkaido university"," in Advanced Applied Informatics (IIAI-AAI), 2016 5th IIAI International Congress on, pp. 547-551, IEEE, 2016.

[22] A. A. Ravankar, S. Imai, M. Shimamura, G. Chiba, T. Takasuka, and Y. Yamanaka, "Nurturing problem-finding skills in graduate students through problem based learning approaches," in Advanced Applied Informatics (IIAI-AAI), 2016 5th IIAI International Congress on, pp. 542-546, IEEE, 2016.

[23] A. A. Ravankar, S. Imai, A. Ravankar, T. Kato, T. Takasuka, T. Tsuji, K. K. Shigetomi, and K. Saito, "Towards better problem finding and creativity in graduate school education: A case study of nitobe school program," in Advanced Applied Informatics (IIAI-AAI), 2018 7th IIAI International Congress on, IEEE, 2018.

[24] H. S. Barrows, "Problem-based learning in medicine and beyond: A brief overview," New directions for teaching and learning, vol. 1996, no. 68, pp. 3-12, 1996.

[25] J.-R. Córdoba and A. Piki, "Facilitating project management education through groups as systems," International Journal of Project Management, vol. 30, no. 1, pp. 83-93, 2012.

[26] T. Mengel, "Outcome-based project management education for emerging leaders-a case study of teaching and learning project management," International Journal of Project Management, vol. 26, no. 3, pp. 275-285, 2008.

[27] M. Alavi, "Computer-mediated collaborative learning: An empirical evaluation," MIS quarterly, pp. 159-174, 1994. 
[28] S. Imai, M. Shimamura, A. A. Ravankar, H. Haga, Y. Kobayashi, and Y. Yamanaka, "Utilization of the student e-portfolio in the graduate education: The case report of" nitobe school program" in hokkaido university," in Advanced Applied Informatics (IIAI-AAI), 2017 6th IIAI International Congress on, pp. 147-152, IEEE, 2017.

[29] J. Cohen, “A power primer.," Psychological bulletin, vol. 112, no. 1, p. 155, 1992.

[30] G. R. Loftus and M. E. Masson, "Using confidence intervals in within-subject designs," Psychonomic bulletin \& review, vol. 1, no. 4, pp. 476-490, 1994.

[31] S. Imai, A. Ravankar, M. Shimamura, T. Takasuka, G. Chiba, and Y. Yamanaka, "Effect of instructors actions and attitudes on students motivation and discussion process in tbl class for graduate students," International Journal of Institutional Research and Management, vol. 1, no. 2, pp. 17-35, 2017. 